\title{
Analysis of floor response spectra of an office building
}

\author{
Norbert Jendzelovsky ${ }^{1, *}$ and Alzbeta Grmanova ${ }^{2}$ \\ ${ }^{1}$ Faculty of Civil Engineering STU in Bratislava, Radlinského 11, 81005 Bratislava, Slovakia \\ ${ }^{2}$ Faculty of Civil Engineering STU in Bratislava, Radlinského 11, 81005 Bratislava, Slovakia
}

\begin{abstract}
The paper deals with the analysis of an office building located in the outskirts of Bratislava, Slovakia. The building consists of one underground floor and five above ground floors that have been roofed by a steel roof structure. The steel structure represents a subtle roofing of areas with air condition units and other technological equipment. For proper design of the steel structure with respect to the seismic loading, it is necessary to prepare floor response spectra for the top floor. A computer model of reinforced concrete structure was created using the Finite Element Method - FEM. Based on the approved recommendations for dynamic loading, seismic load of the building was defined in the form of a synthetic three-component accelerogram at free field level. The calculations of seismic response spectra were made assuming a linearly elastic behavior of the building structure without considering the elastoplastic effects during the earthquake. The calculation of transient analysis was performed for a three-component synthetic accelerometer in ANSYS software.

Acceleration time responses in three orthogonal directions (two horizontal and one vertical) were obtained for 6 selected points of the top floor. The obtained values of acceleration were compiled by additional software in order to obtain the resulting floor spectra. Subsequently, the envelope of the floor spectra was created, which has been taken into account in the design of a steel roof structure.
\end{abstract}

\section{Introducion}

The office building located in the outskirts of Bratislava, Slovakia, consists of one underground floor and five above ground reinforced concrete floors that have been roofed by a steel roof structure. The steel structure represents a subtle roofing of areas with air condition units and other technological equipment. The dimensions of a ground plan are $101.2 \mathrm{~m} \times 130 \mathrm{~m}$. From the structural viewpoint, the building consists of two dilatation units (unit A and unit B). This paper is focused on the dilatation unit A, which is presented in Fig. 1. Its dimensions are approximately $101.2 \times 63.5 \mathrm{~m}$. The construction unit (underground floor 1 , floors 1 to 5) is made from reinforced concrete. The steel roof

\footnotetext{
* Corresponding author: norbert.jendzelovsky@stuba.sk
} 
structure is situated above the level of the top floor. Its design was determined by the presented analysis of floor response spectra.

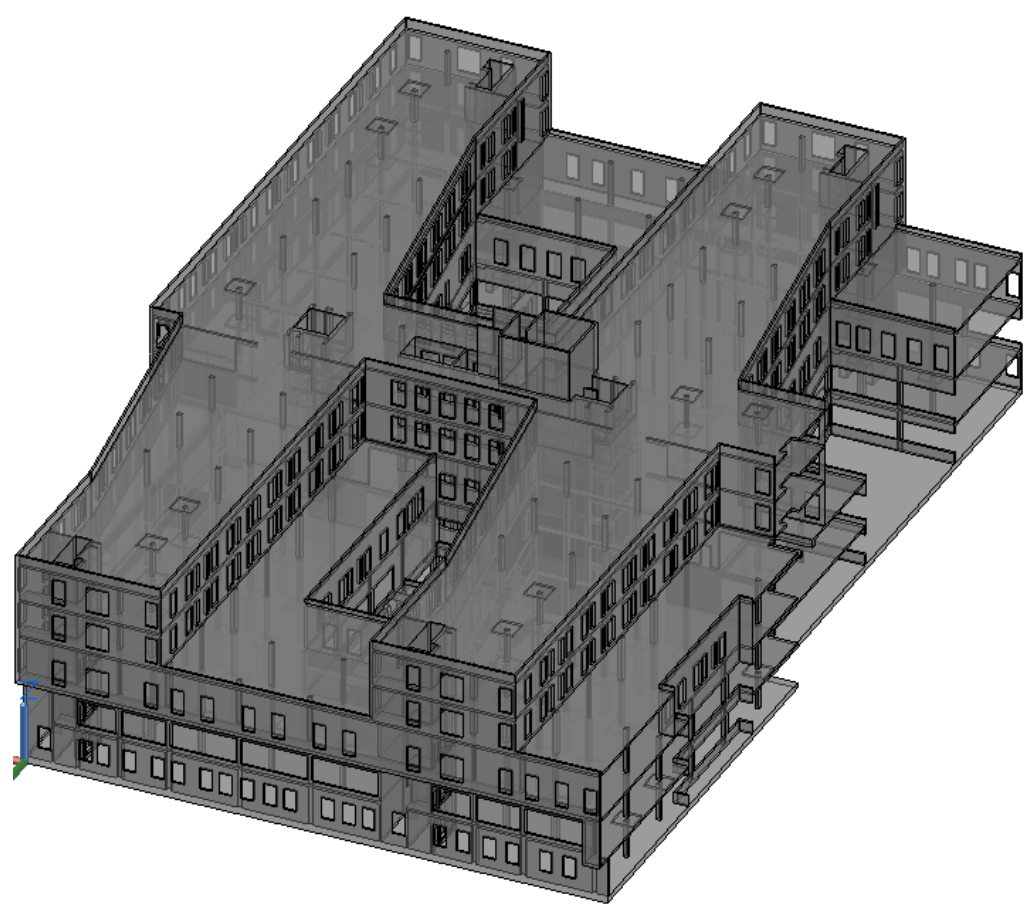

Fig. 1. Dilatation unit "A“, axonometric view.

Based on available plans, the computer structural model was created using the Finite Element Method - FEM. Bearing walls had been modeled in accordance with the design project as reinforced concrete walls of various thicknesses $(150-350 \mathrm{~mm})$ made from a concrete of different classes. Beams had been modeled as reinforced concrete beams of different shapes (circular, trapezoidal, square) and made from a concrete of different classes. The girders have been designed as reinforced concrete ones; they increase horizontal stiffness of the building and optimize the method of supporting of plates. They are situated in floors No. $1-3$ and are of various dimensions. All girders are manufactured from concrete class $\mathrm{C} 30 / 37$. Ceiling plates are designed as reinforced concrete ones supported by beams and walls, in some cases by beams with heads. Particular plate thickness varies between 200 and $250 \mathrm{~mm}$ in above-ground floors and between $250-540$ $\mathrm{mm}$ in the underground floor.

The finite element model (Fig. 2) was modeled considering the rigid coupling of plates, walls, girders, beams, and heads into a single structural unit. Material characteristics necessary for the seismic analysis of a building were taken in accordance with corresponding standards $[1,2]$ and they are: specific weight $\gamma=2600 \mathrm{kN} / \mathrm{m}^{3}$, elasticity modul $\mathrm{E}_{\text {dyn }}=33$ to $40.3 \mathrm{GPa}(\mathrm{C} 20 / 25$ to $\mathrm{C} 30 / 37)$.

Similar analyses of structures have been presented also in works $[3,4,5,6,7]$. 


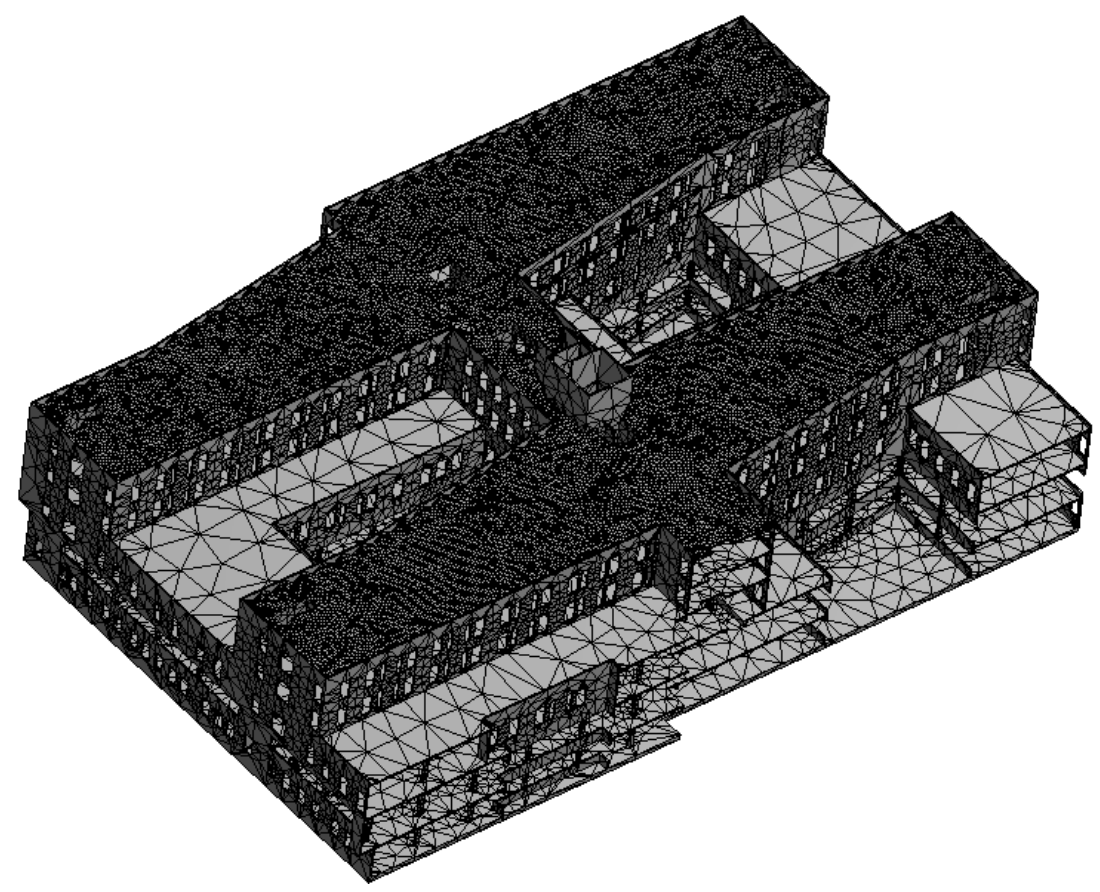

Fig. 2. Finite element mesh generated on a structure.

\section{Methodology of the analysis}

After creating the finite element model and defining the necessary characteristics, it was possible to proceed with the analysis itself.

\section{Methodology:}

1. Definition of permanent load and payload followed by creation of masses.

2. Definition of seismic load - definition of synthetic accelerograms compatible with the response spectra (prof. Králik).

3. Transient analysis- method of integration of motion equations in time considering the seismic excitation of a structure.

4. Compilation of results of acceleration of selected floor nodes, generation of response spectra individually for each node, generation of floor response spectrum and response spectra envelope.

\section{Load detemination}

During the excitation of a structure by seismic acceleration it is necessary to consider, in addition to the self-weight of a bearing structure, also other masses that participate in the vibration. These are mainly: weight of the steel roof structure, weight of floors, gradient layers, soffits, walls, technological equipment and humans.

Interaction of the self-weight of the bearing structure, permanent loads, and payloads during the supposed earthquake was considered within single seismic design combination based on which, the resulting acceleration of individual floors had been calculated.

The payload had been reduced in accordance with the standard [1] using the coefficient $\psi_{2}$. 
Based on approved recommendations in [8], the original seismic loading of the building was defined in the shape of a synthetic three-component accelerogram in the level of a free field.

The methodology was taken from the work of Ing. Masopust [9]. For purposes of analysis of the time response of building and calculation of the floor spectrum it was necessary to define synthetic accelerograms compatible with response spectra. Based on the assumptions mentioned above, prof. Kralik has created synthetic response spectra and subsequently derived synthetic accelerograms consisting of three components of excitation in space. Seismic calculations must be performed for three orthogonal components of the seismic excitation (two horizontal and one vertical) that coincide with the principal axes of the object under investigation. Calculations of the seismic floor response spectra should be made assuming the linearly elastic behavior of the building structure without considering the elasto-plastic effects during the earthquake.

\section{Three-component response spectrum and a corresponding accelerogram for:}

longitudinal direction of excitation:
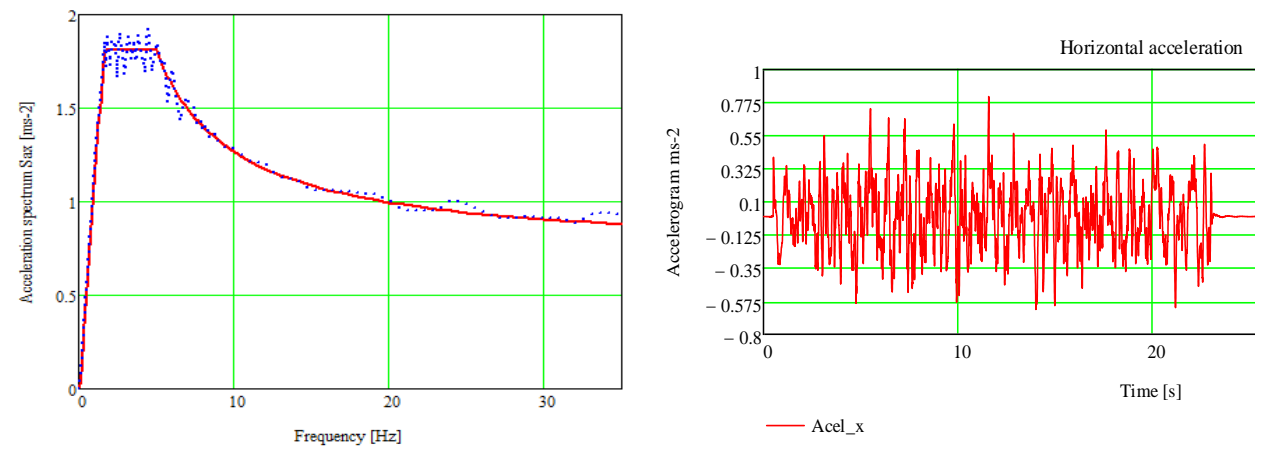

Fig. 3. Standard spectrum - red line, synthetic spectrum - blue line, synthetic accelerogram - red line.

lateral direction of excitation:
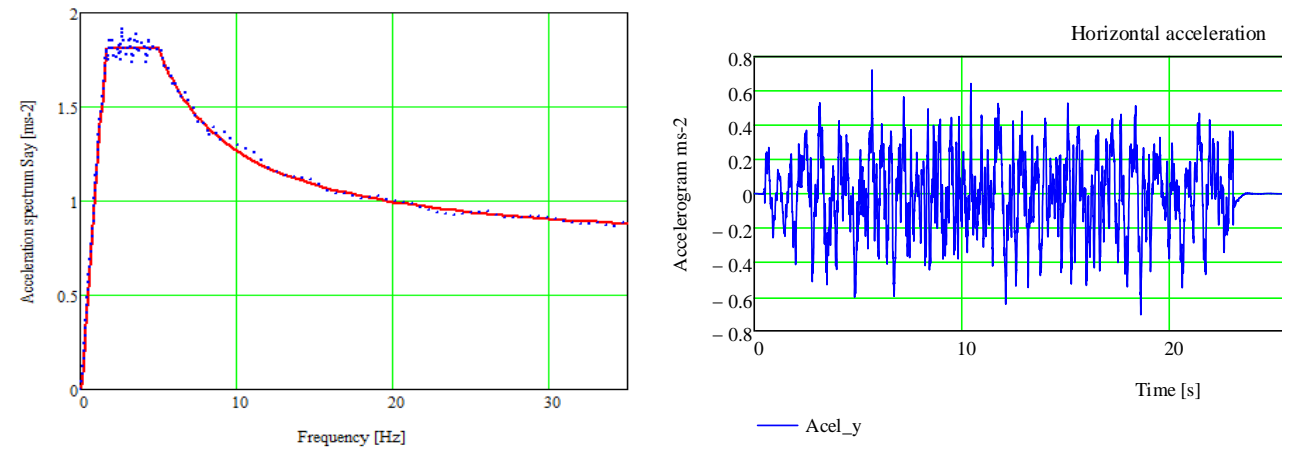

Fig. 4. Standard spectrum - red line, synthetic spectrum - blue line, synthetic accelerogram - blue line. 
vertical direction of excitation:
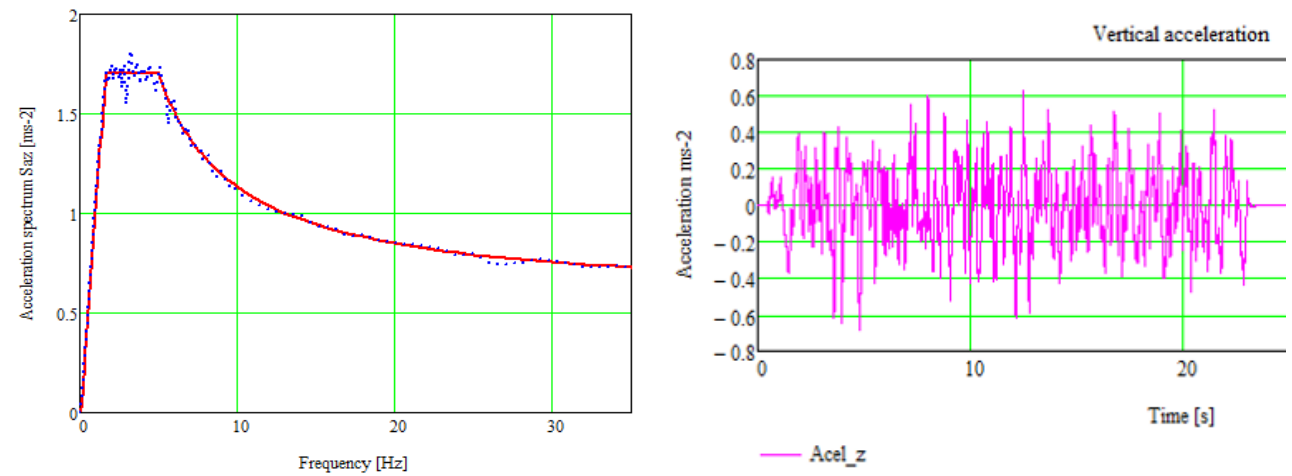

Fig. 5. Standard spectrum - red line, synthetic spectrum - blue line, synthetic accelerogram - magenta line.

\section{Transient analysis of the seismic excitation}

Through integration of motion equations in time, the accelerations of structure had been calculated in three orthogonal directions considering three-component seismic excitation of a structure using three synthetic accelerograms. The calculation had been performed once (for a three-component synthetic accelerogram) using the ANSYS software.

Floor spectrum of fifth floor had been calculated from obtained accelerograms in selected nodes as a response to the excitation accelerograms. Usually, at least five nodes on a floor have been considered - four nodes in corners, one node in the middle. In this case six nodes were selected to investigate the structural response. For response calculation the method of integration of motion equations in time considering the proportional damping $7 \%$ in the structure had been used which is in accordance with approved methodology, see [9]. Nodes selected for the calculation of floor spectra indicate the characteristic positions that represent movement of the particular floor.

\section{Results of analysis of seismic excitation time history}

As a result of calculation, time responses of accelerations in three orthogonal directions (two horizontal and one vertical) had been obtained for six selected points on the fifth floor of an investigated structure.

Due to the large amount of obtained results, in this paper we do not present specific accelerations for each node and each excitation direction. The acquired results were, using additional software, compiled to obtain resulting floor spectra in a given node. In Fig. 6 one can see the response spectrum of the longitudinal excitation direction. Similar spectra have been obtained for lateral and vertical directions as well. 


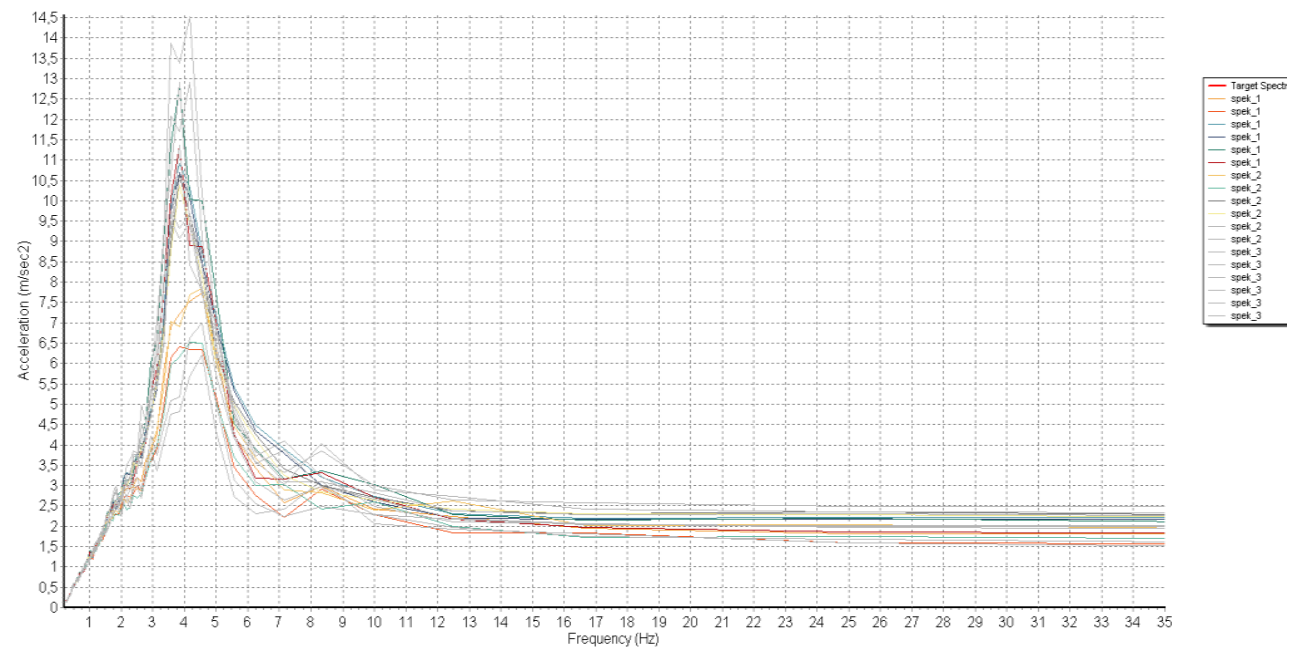

Fig. 6. Longitudinal direction - response spectrum for six individual points.

\section{Conclusion}

The acquired results of response spectra had been, using some additional software, compiled to obtain complete envelopes of the floor spectrum. The peak cutting methodology was applied according to [9] to reduce the value to $85 \%$. Two floor spectra have been presented in each figure for 5\% and 10\% damping. Following up, floor spectra for two horizontal directions (Figs. 7 and 8) and a vertical direction (Fig. 9) of the structure have been shown. Resulting envelopes of spectra have been provided to designers for further design of the steel roofing structure.

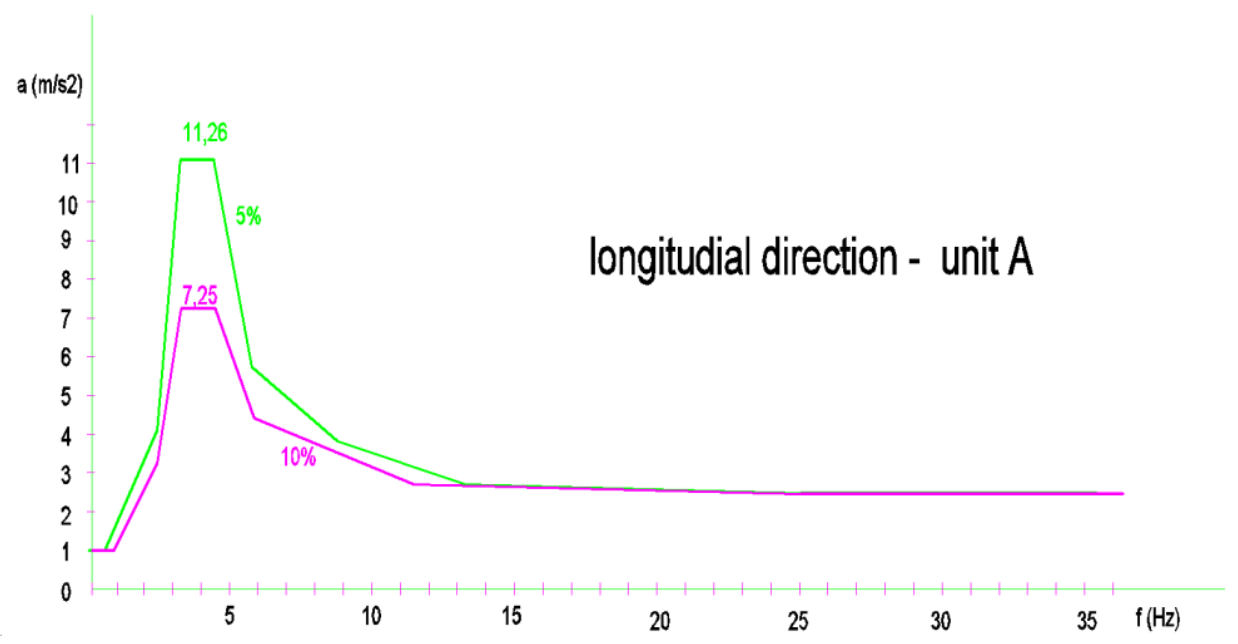

Fig. 7. Envelope of spectra - longitudinal direction. 


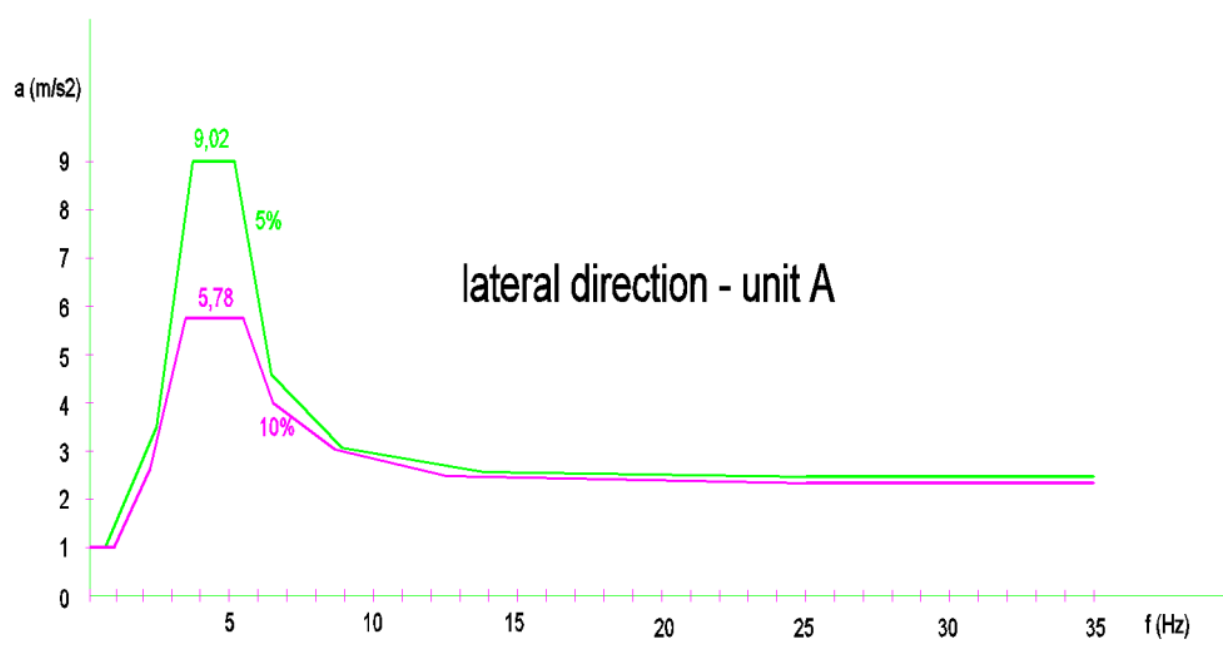

Fig. 8. Envelope of spectra - lateral direction.

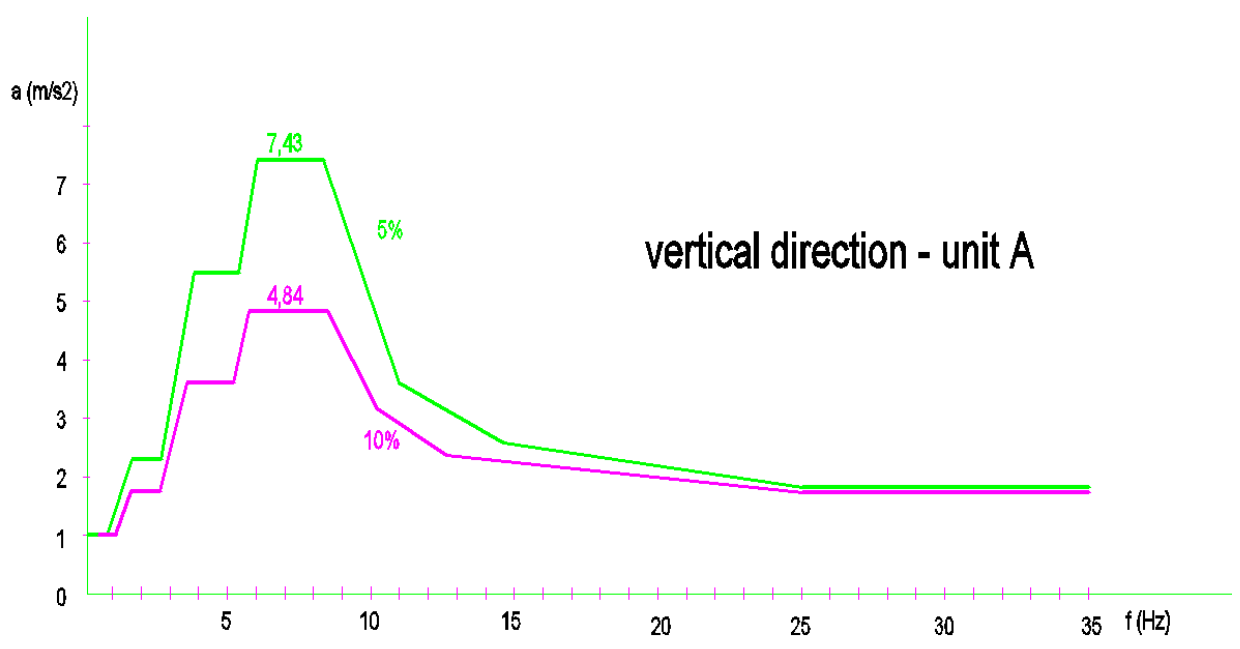

Fig. 9. Envelope of spectra - vertical direction.

\section{Acknowledgment}

This paper was supported by Grant Agency VEGA, project No. 1/0412/18 and No. $1 / 0265 / 16$.

\section{References}

1. STN EN-1991-1-1, Eurocode 1. Actions on structures. Part 1-1: General actions. Densities, self-weight, imposed loads for buildings.

2. STN EN 1992-1-1, Eurocode 2. Design of concrete structures - Part 1-1: General rules and rules for buildings.

3. Kotrasová, K. MATEC Web Conference, CSCC2018 210 (2018), 04003 
4. Kotrasová, K. - Leoveanu, I. S. - Kormaníková, E. Buletinul AGIR 18 (3) (2013)

5. Salajka, V. - Hradil, P. - Kala, J. Applied Mechanics and Materials, (2013) Vol 284287, pp. 1247-1250.

6. Hradil, P. -Salajka, V. - Kala, J, MATEC Web Conference DYN-WIND 2017107 (2017), 00010

7. Brozovsky, J. - Cajka, R. - Koktan,J. IOP CUTE 2018, 143 (2018), 012036

8. IAEA, Safety Series 50-SG-S1, Earthquake and Associated Topics in Relation to Nuclear Power Plants Siting. Rev.1., IAEA, Vienna, (1991).

9. Masopust, R. - Podroužek, J. Requirements for re-evaluation of seismic resistance of structures and equipment of EMO - Block 1 and 2, S\&A, ŠKODA Praha, (1995) (in Czech). 